\title{
The effect of specimen size on residual stresses in friction stir welded aluminum components
}

\author{
Wulf Pfeiffer ${ }^{1, a^{*}}$, Eduard Reisacher ${ }^{1, b}$, Michael Windisch ${ }^{2, \mathrm{c}}$, Markus Kahnert ${ }^{2, \mathrm{~d}}$ \\ ${ }^{1}$ Fraunhofer Institute for Mechanics of Materials IWM, 79108 Freiburg, Germany; \\ ${ }^{2}$ MT Aerospace AG, 86153 Augsburg, Germany \\ awulf.pfeiffer@iwm.fraunhofer.de, beduard.reisacher@iwm.fraunhofer.de, \\ cmichael.windisch@mt-aerospace.de, 'dmarkus.kahnert@mt-aerorspace.de
}

Keywords: friction stir welding, aluminum, residual stresses, size effect.

Abstract. Friction stir welding (FSW) is a well-known technique which allows joining of metal parts without severe distortion. Because FSW involves less heat input relative to conventional welding, it may be assumed that cutting specimens from larger friction stir welded components results in a negligible redistribution of residual stresses. The aim of the investigations was to verify these assumptions for a welded aluminum plate and a circumferentially-welded aluminum cylinder. Strain gage measurements, X-ray diffraction and the incremental hole drilling method were used.

\section{Introduction}

Friction stir welding (FSW) has been finding an increasing interest for joining of space and aircraft components made from high strength aluminum alloys. A comprehensive overview about the knowledge that has been built up with respect to the friction stir welding (FSW) of aluminum alloys is given by [1].

The Friction Stir welding process is carried out by a rotating weld tool consisting of a shoulder and a pin. When the welding tool is pressed under high axial load on the part surface and the tool pin is inserted into the parts the surrounding material is then plasticized. Together with applying a feed along the joint line to the welding tool the weld seam is produced. All in all the process may be compared to an extrusion of the plasticized material around the rotating tool pin. Although the real temperatures being present in the weld nugget and the adjacent zones during the welding process are still a matter of discussion it can be stated that welding temperature is below the melting temperature of the materials. In case of aluminum, it is assumed that temperatures do not travel over $500^{\circ} \mathrm{C}[2]$.

Residual stresses occurring as a result of FSW are lower than those occurring as a result of thermal welding, because less shrinkage occurs. Experimental residual stress investigations have been performed on specimens with various geometries using different techniques. Results obtained using synchrotron or neutron diffraction indicate that longitudinal residual stresses tend to show the largest variation, being most tensile in the heat affected zone (HAZ), lower in the nugget and compressive in the parent plate [1]. The transverse residual stresses are generally reported to be much lower than those in the longitudinal direction.

Investigations of the redistribution of the residual stresses have been performed on butt welds in thin [3] - [5] and thicker aluminum plates [6]. Experimental investigations on thin (3 mm) plates indicated that the weld length must be approximately 8 to 12 times the diameter of the FSW-tool for the residual stress state not to be influenced significantly by removal of the specimen. Experimental investigations on butt welds in thick $(25 \mathrm{~mm})$ plates were performed on post weld heat treated plates already containing low residual stresses before cutting. Complementary numerical investigation indicated that the plate length should be 8 times the plate thickness to avoid significant stress relaxation.

The purpose of our investigations was to experimentally evaluate (I) the magnitude and (II) the orientation of the residual stress changes in a 8mm-thick FS welded plate and a large FS welded cylinder. The cut plates had dimensions typical of samples used in fracture mechanical tests. 


\section{Experimental Details}

Investigated Components. Two different types of components were investigated: an $8.5 \mathrm{~mm}$ thick FSW-plate with the dimensions $500 \mathrm{~mm} \times 300 \mathrm{~mm}$ and an $8 \mathrm{~mm}$ thick ring with a diameter of $5.4 \mathrm{~m}$ and height of $175 \mathrm{~mm}$. The plate and ring were welded longitudinally and circumferentially respectively. The welds were located in the centers of the components. The plate material was AA 2219 T87 whereas the ring material was AA 2219 T851. The yield strength of the materials varied from $170 \mathrm{MPa}$ in the nugget, $270 \mathrm{MPa}$ in the $\mathrm{HAZ}$ and $340 \mathrm{MPa}-370 \mathrm{MPa}$ in the base metal.

Friction Stir Welding. The weld seam was produced using a conventional welding tool, the so called Pin-Shoulder-Tool which consists of one shoulder and one pin. In Fig. 1 the typical structure of the weld applied to the ring with a weld thickness of $8 \mathrm{~mm}$ is displayed. The different zones can be clearly indicated and are described below. On the crown side the width of the weld seam is defined by the shoulder diameter of about $25 \mathrm{~mm}$ and decreases with the depth of the weld. The size of the stirred zoned (A), the weld nugget, is mainly affected by the pin diameter of about 8 to $12 \mathrm{~mm}$.

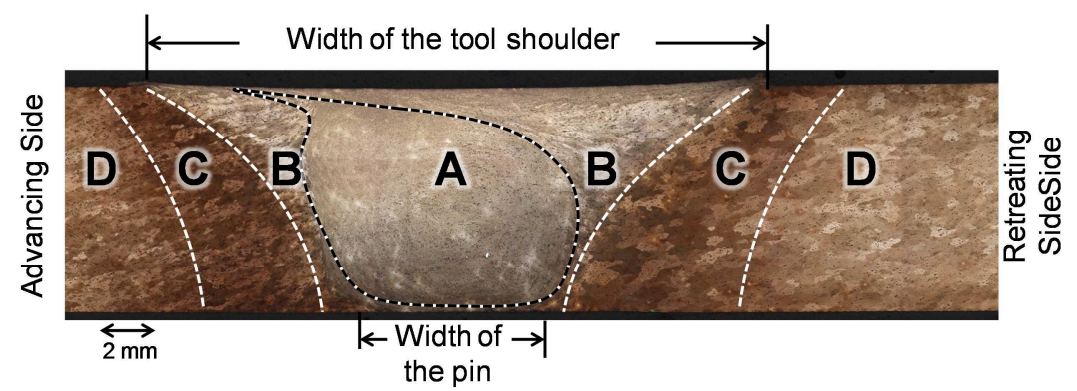

Fig. 1: Section of the Friction Stir Weld seam applied to the ring. The different zones are indicated by dashed lines. The Zone A is called the stir zone or nugget in which a dynamic recrystallization takes place and a fine grain structure can be observed. The zone B is representing the thermo mechanical affected zone (TMAZ) in which the process force and heat are causing a significant grain deformation. Zone $\mathrm{C}$ is the heat affected zone (HAZ) and D is the coarse grained base material.

Specimen Preparation And Location Of Measurements. A rectangular specimen of the dimensions $100 \mathrm{~mm} \times 100 \mathrm{~mm}$ were cut from the plate, whereas a segment with an arc-length of $990 \mathrm{~mm}$ was cut from the ring. Strains released during the cutting were measured by strain gages applied near the locations where the residual stress measurements were performed. The measurement locations for the depth probing were selected on basis of surface residual stresses. They showed that the maximum residual stresses occurred at the weld center and close to the fusion lines.

Due to the slight weld burr near the fusion lines, the points where residual stresses were determined were first flattened by fine grinding followed. Electrochemical polishing was subsequently used to remove $0.2 \mathrm{~mm}$ of material in order to eliminate the influence of grinding and of the machining of the original surfaces.

Determination Of Residual Stresses. Near surface residual stresses were determined using the X-ray diffraction (XRD). The spot diameters were $1 \mathrm{~mm}$ in the case of the plate and $2 \mathrm{~mm}$ in case of the ring segment. CuK $\alpha$ radiation with an effective penetration depth of $37 \mu \mathrm{m}$ was used to determine the lattice strains from diffraction line positions of the $\{422\}$ - lattice planes. Calculation of the stresses was performed based on the $\sin ^{2} \psi$-technique [7] using a Young's modulus E of 70 GPa und Poisson's ration $v=0.3$.

Depth probing was performed using the incremental hole drilling technique (IHD) and the differential evaluation method given in [8]. A hole diameter of $0.9 \mathrm{~mm}$ was selected which allowed reliable stress calculation to a depth of $0.6 \mathrm{~mm}$. The constants of elasticity used for XRD analysis were also used for the IHD measurements. It should be noted that stresses of more than $60 \%$ of the yield strength partially result from localized plastic deformation near the walls of the hole and therefore should not be taken into account. 


\section{Results}

Flat Plate Weld. Significant compressive stresses of $\sim 70 \mathrm{MPa}$ developed in longitudinal direction at both sides of the remaining specimen due to cutting. In the transverse direction smaller tensile stresses of $\sim 30 \mathrm{MPa}$ were created. Since the stresses at the top and root side of the specimen were similar, it can be concluded that no significant bending occurs due to cutting. These stress components are included in the results of the subsequent residual stress measurements for the removed specimens (see Fig. 2 and Fig. 3).
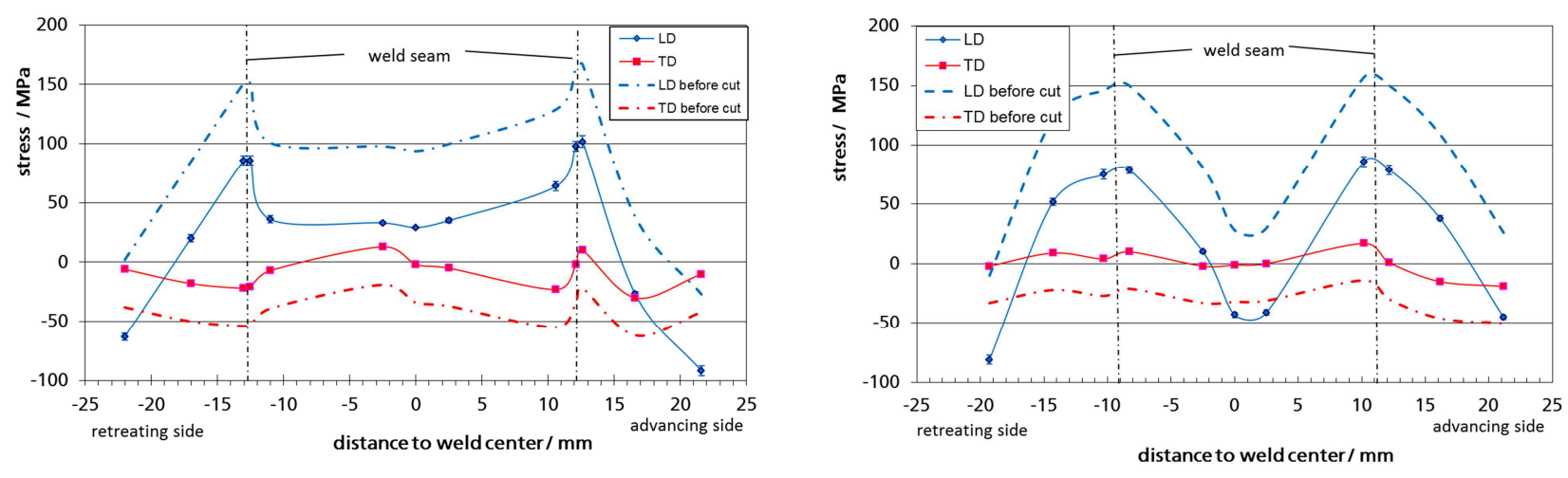

Fig. 2: Distribution of surface residual stresses at the weld crown side (left) and the weld root side (right) of the specimen cut from the plate, determined by XRD. Dashed lines denote the residual stress distribution before cutting. $\mathrm{LD}=$ longitudinal direction, $\mathrm{TD}=$ transverse direction.

At the "weld center" and "fusion line" (which is the borderline of the weld seam) the distributions of longitudinal residual stresses within a depth of $0.6 \mathrm{~mm}$ below the surfaces are shown in Fig.3 (Transverse residual stresses will be reported elsewhere).
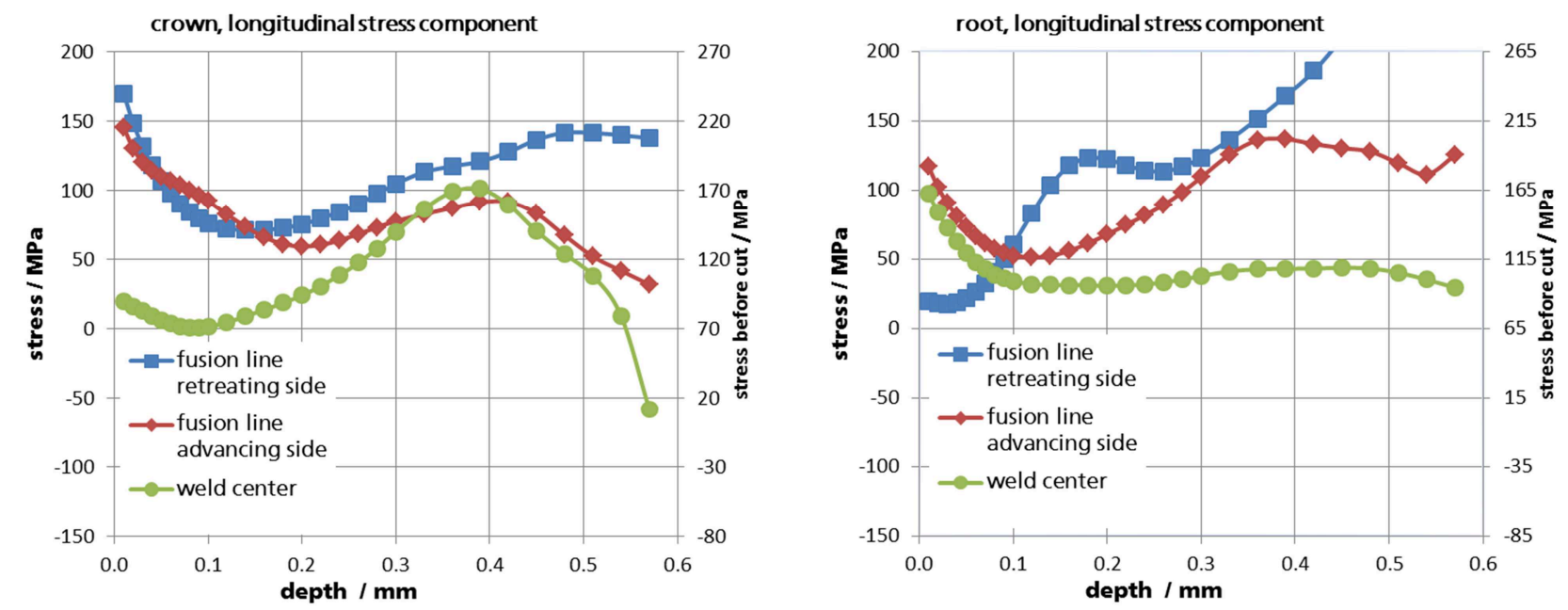

Fig. 3: Depth distribution of longitudinal residual stresses of the specimen cut from the plate determined by IHD. Left $=$ weld crown, right $=$ weld root. The secondary ordinate denotes the scaling for the non-cut plate.

The results show that the high tensile residual surface stresses, acting in the longitudinal direction near the fusion lines, decline within the first $0.6 \mathrm{~mm}$ below the surface of the crown side. This is also true for the advancing side at the root side of the plate but not for the retreating side. At the retreating fusion line side of the plate's root side tensile peaks are found below the surface. In addition, these residual stress components show tendencies to again increasing tensile residual stresses with depth. 
The residual stresses in the weld center develop differently with respect to depth at the crown and root side. At the crown side, longitudinal residual stresses show a maximum at a depth of $0.4 \mathrm{~mm}$. At the root side the longitudinal residual stresses reduce with increasing depth.

Only few of the stress values exceed the confidence limit of the IHD method ( 100 MPa for the weld metals, $\sim 160 \mathrm{MPa}$ for the HAZ). Thus, the determined stress distributions should represent the real residual stress states.

Circumferential Cylinder Weld. Only small stresses of up to $20 \mathrm{MPa}$ were generated due to cutting. At the inner side of the ring (weld root) all stress components are compressive, whereas at the outer side (weld crown) the transverse components tend to be tensile. These stress components are included in the results of the subsequent residual stress measurements on the part cut out of the cylinder.

The XRD investigations were influenced by texture effects especially near the fusion lines in the weld metal and the heat affected zone. Thus, information is only available regarding the surface residual stress state in the weld nugget; see Fig. 4. Both the crown and the root side of the weld nugget show tensile residual stresses up to $110 \mathrm{MPa}$ in the longitudinal direction. The transverse residual stresses are small and generally compressive. The residual stress distribution measured in the weld nugget at the outer surface of the ring-segment (weld crown, Fig. 4) indicates a reduction of tensile residual stresses already within the nugget near the fusion line. The transverse residual stress components tend to be more compressive near the fusion line and in the weld center. This is in contrast to the results for the FSW plates, in which the highest tensile residual stresses were found in the region around the fusion line, with lower residual stresses occurring in the weld center.
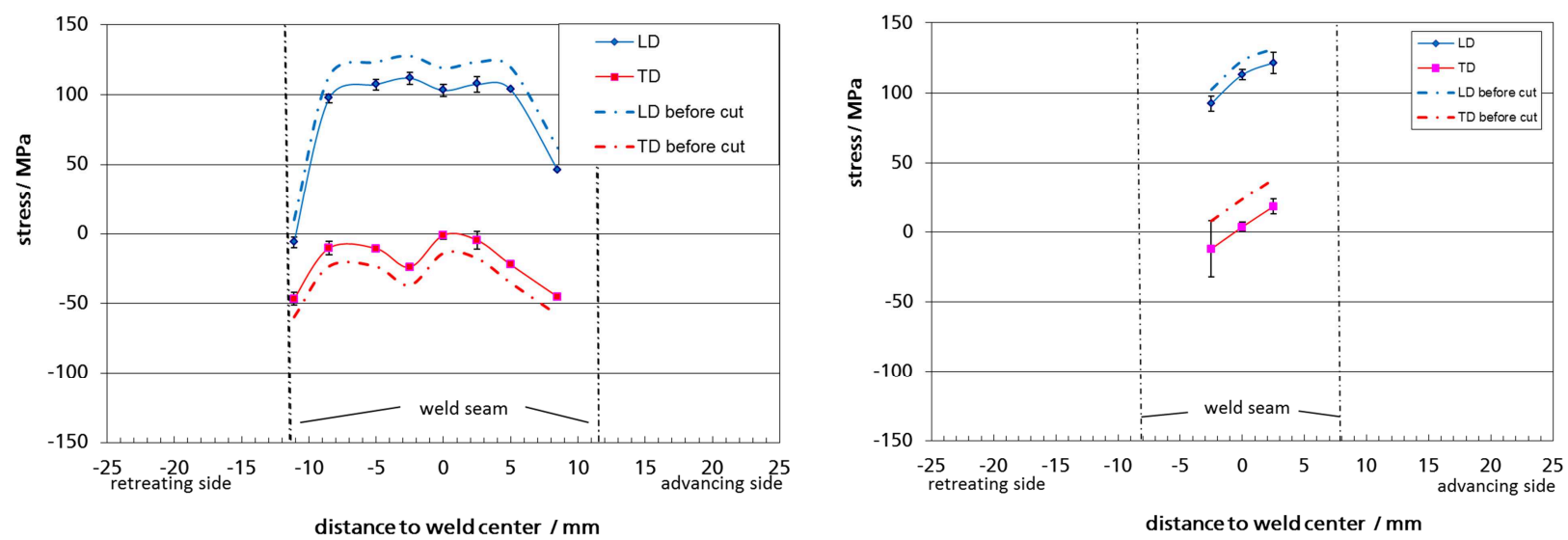

Fig. 4: Distribution of surface residual stresses at the outer side of the ring segment (weld crown, left), and at the inner side of the ring segment (weld root, right), determined by XRD. Measurements outside the weld metal failed due to strong texture effects. Dashed lines indicate the residual stress distribution before cutting. $\mathrm{LD}=$ longitudinal direction, $\mathrm{TD}=$ transverse direction.

The XRD results for the outer surface (weld crown) indicated that the maximum residual stress occurred within the nugget adjacent to the fusion lines. Thus, depth probing of residual stresses by the IHD-method was performed $8 \mathrm{~mm}$ beside the weld center ( $3.5 \mathrm{~mm}$ from the fusion line).

The results of depth probing of longitudinal residual stresses are summarized in Fig.5. Again it should be noted that stress levels above $60 \%$ of the yield strength cannot be accurately determined using the IHD method. All residual stress components, measured in the longitudinal direction, in the weld center and near the fusion line, at the crown and root side of the weld were quite high near the surface and may be as high as the yield strength. They then drop within the first $0.15 \mathrm{~mm}$ depth. At roughly $0.35 \mathrm{~mm}$ depth the residual stresses show a significant tensile peak. The peak is very pronounced at the advancing side of the weld and may be as high as the yield strength of the material. Towards deeper regions the longitudinal residual stress components tend to be compressive. 

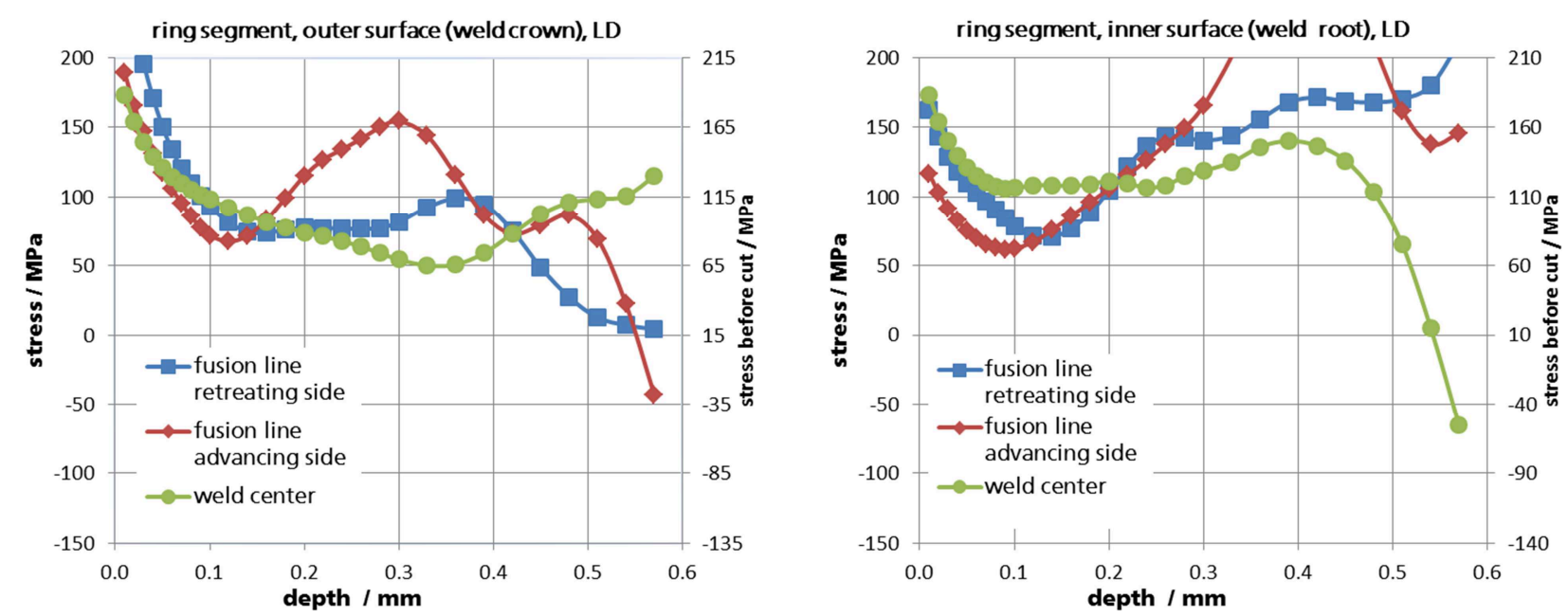

Fig. 5: Depth distribution of longitudinal residual stresses of the segment cut from the ring determined by IHD. Left $=$ weld crown, right $=$ weld root. The secondary ordinate denotes the scaling for the non-cut ring.

\section{Discussion And Conclusions}

The friction stir welded plate and ring show similar distributions of near-surface transverse residual stresses. Thus, residual stress investigations on plates may be assumed to be a representative and conservative assumption for circumferential cylinder welds concerning the transverse near-surface residual stresses. The maximum longitudinal near surface residual stresses are also similar for the flat plate weld and the circumferential cylinder weld. Some differences exist for locations of the maxima and the distributions.

In evaluating the residual stresses using the hole drilling method, the complexity of the microstructure especially at the borders of the stirred material close to the fusion lines must be considered (see Fig. 1). The heterogeneous microstructure also raises doubts about the results for depths greater than $0.3 \mathrm{~mm}$ to $0.5 \mathrm{~mm}$. Interpretation and comparison therefore should be based mainly on the results for the first $0.3 \mathrm{~mm}$.

The differences in the residual stresses in the weld nuggets of the plate and ring in weld (longitudinal) direction are explained as follows:

a) the weld nugget yield stress is significantly lower than those for the HAZ and base material . Consequently, this permits stress redistribution if free shrinkage is not restrained.

b) the flat plate allows shrinkage both transverse and parallel to the weld, whereas for the circumferential cylinder weld shrinkage in weld direction is restrained because this is possible only with reduction of cylinder radius.

Cutting of large components into smaller specimens primarily affects the long-range residual stresses. The amount of residual stress shift after cutting of parts with widths larger than $100 \mathrm{~mm}$ is comparable to the shift of longitudinal residual stress components (up to $70 \mathrm{MPa}$ ) for the flat plate weld and the circumferential cylinder weld. Shift of transverse residual stresses (up to $30 \mathrm{MPa}$ ) differs in amount and in direction for the flat plate and the cylinder weld.

The part of the plate investigated here is well outside the "secure" limit of 8-12 times the diameter of the FSW-tool [3] - [5] but well within the recommendation of [6] saying that the plate length should be at least 8 times the plate thickness to avoid a significant change of residual stresses. In the case of the segment cut from the ring no significant change of residual stresses should occur at all (assuming that rings behave similar as plates).

In the case of the flat plate weld, the redistribution of the original residual stress state in the large plate significantly increases the longitudinal tensile residual stresses near the fusion line towards the yield strength. The increase of the (smaller) transverse residual stresses is only $50 \%$ of that for the longitudinal residual stresses and pushes the residual stresses towards compression. 
Tests performed with specimen of widths larger than about $60 \mathrm{~mm}$ still include a significant portion of original residual stress of the component. This applies especially for fracture mechanics tests as fatigue and crack growth and stress corrosion cracking (SCC).

Tests performed with material from flat plates, loaded transverse to the welding direction are representative of circumferential cylinder weld configurations and are conservative due to the addition of a small amount of tensile residual stress.

Tests performed with parts from flat plates, loaded parallel to the welding direction are representative of circumferential cylinder weld configurations for the fusion lines but significantly underestimate the residual stresses in the circumferential cylinder weld nugget.

Fracture toughness testing is not affected as fracture occurs beyond yield strength where relaxation is completely observed. The evaluation of residual stresses on fatigue and crack growth by tests performed on parts of components is not straightforward. Such an evaluation has to distinguish between crack initiation and crack growth. When the crack has developed to a significant crack depth and length, the crack will travel through volumes with a complex stress field. Nevertheless, investigations on the effect of low plasticity burnishing on the high cycle fatigue behavior (4-point bending) of AA 2219 show a significant enhancement of fatigue life due to compressive residual stresses [9]. Conversely it may be concluded that the compressive stresses parallel to the welding direction created during the cutting process will lead to non-conservative results in fatigue tests.

The effect of residual stresses on SCC of FS-welded AA 2219 may be less pronounced. Slow strain rate testing (SSRT) performed on FS-welded and TIG-welded AA 2219 indicated that little environmentally enhanced degradation occurs in AA 2219 and is related to a pure electro-chemical corrosion process than to a true SSC-process [10] - [13]. Thus, residual stresses may contribute little to SCC.

\section{References}

[1] P. L. Threadgill et al., Friction stir welding of aluminium alloys, International Materials Reviews, 54(2009) 49-93.

[2] H. R. Shercliff, P. A. Colegrove, in: R. S. Mishra et al. (Eds.), Friction stir welding and processing, ASM International, Materials Park, OH, 2007, pp. 187- 217.

[3] J. Altenkirch et al., Powder Diffraction, 24(2009) 31-36.

[4] J. Altenkirch et al., Mater. Sci. Engng A(2008) 16-24.

[5] M. Law et al., Journal of Strain Analysis for Engineering Design 45(2010) 567.

[6] M. B. Prime at al., Acta Mater., 54(2006) 4013- 4021.

[7] E. Macherauch, M. Müller, Zeitschrift für Angewandte Physik 13(1961) 305-312.

[8] T. Schwarz, H. Kockelmann, Messtechnische Briefe 29, 2(1993) 32 - 38, HBM GmbH, Darmstadt, Germany.

[9] P. Prevéy et al., Intern. Surface Engineering Conference, Oct. 7-10, 2002, Columbus, OH.

[10] A. Venugopal ez al., Metallurgical and Materials Transactions A 43A (2012) 3135-3148.

[11] W. Hu, EI. Meletis, Mater. Sci. Forum, 331-337 (2000) 1683-1688.

[12] P. Bala Srinivasan et al., J. Alloy. Compd., 492(2009) 631-37.

[13]C.S. Paglia and R.G. Buchheit, Materials Science and Engineering A 429(2006) 107-114. 